\title{
Endoplasmic reticulum stress mediating downregulated StAR and 3-beta-HSD and low plasma testosterone caused by hypoxia is attenuated by CPU86017-RS and nifedipine
}

Gui-Lai Liư ${ }^{\dagger}$ Feng Yư ${ }^{\dagger}$ De-Zai Dai, Guo-Lin Zhang, Can Zhang and Yin Dai

\begin{abstract}
Background: Hypoxia exposure initiates low serum testosterone levels that could be attributed to downregulated androgen biosynthesizing genes such as StAR (steroidogenic acute regulatory protein) and 3-beta-HSD (3-betahydroxysteroid dehydrogenase) in the testis. It was hypothesized that these abnormalities in the testis by hypoxia are associated with oxidative stress and an increase in chaperones of endoplasmic reticulum stress (ER stress) and ER stress could be modulated by a reduction in calcium influx. Therefore, we verify that if an application of CPU86017-RS (simplified as RS, a derivative to berberine) could alleviate the ER stress and depressed gene expressions of StAR and 3-beta-HSD, and low plasma testosterone in hypoxic rats, these were compared with those of nifedipine.

Methods: Adult male Sprague-Dawley rats were randomly divided into control, hypoxia for 28 days, and hypoxia treated (mg/kg, p.o.) during the last 14 days with nifedipine (Nif, 10) and three doses of RS $(20,40,80)$, and normal rats treated with RS isomer (80). Serum testosterone (T) and luteinizing hormone (LH) were measured. The testicular expressions of biomarkers including StAR, 3-beta-HSD, immunoglobulin heavy chain binding protein (Bip), double-strand RNA-activated protein kinase-like ER kinase (PERK) and pro-apoptotic transcription factor C/EBP homologous protein (CHOP) were measured.

Results: In hypoxic rats, serum testosterone levels decreased and mRNA and protein expressions of the testosterone biosynthesis related genes, StAR and 3-beta-HSD were downregulated. These changes were linked to an increase in oxidants and upregulated ER stress chaperones: Bip, PERK, CHOP and distorted histological structure of the seminiferous tubules in the testis. These abnormalities were attenuated significantly by CPU86017-RS and nifedipine.
\end{abstract}

Conclusion: Downregulated StAR and 3-beta-HSD significantly contribute to low testosterone in hypoxic rats and is associated with ER stress which mediates testis damage caused by oxygen deprivation. CPU86017-RS is potential in ameliorating hypoxia-induced testicular injuries, possibly by its calcium antagonist effects on the testis.

Keywords: ER stress, testosterone, hypoxia, StAR, 3-beta-HSD, CHOP, PERK, Bip, testes, CPU86017

\section{Background}

Male hypogonadism is defined as low serum testosterone under $300 \mathrm{ng} / \mathrm{dL}$ that has been considered as one of the major concerns in the modern society [1]. Regarding the possible mechanisms underlying, oxidative stress in the

\footnotetext{
* Correspondence: dezaidai@vip.sina.com

† Contributed equally

Faculty of Pharmacy, China Pharmaceutical University, Nanjing, 210009, China
}

(c) 2012 Liu et al; licensee BioMed Central Ltd. This is an Open Access article distributed under the terms of the Creative Commons Attribution License (http://creativecommons.org/licenses/by/2.0), which permits unrestricted use, distribution, and reproduction in any medium, provided the original work is properly cited. testis serves as the main causal factor actively involved in the pathogenesis of male hypogonadism [2]. Among various etiologies, hypoxia causes oxygen deprivation in the testis contributing to reduced production of androgen, in which a combination with pro-inflammatory factors including ET-1 (endothelin -1), leptin and ROS in initiating testicular abnormalities is likely involved [3]. Oxygen deprivation induces a series of mitochondria dysfunction facilitating an increase of oxidants and a decrease of 
antioxidants, resulting in an alteration of the redox system, then, oxidative stress occurs $[4,5]$. In the oxygen deprived condition, an increase in transcription promoting factors exacerbates the production of inflammatory and pro-inflammatory cytokines likely caused by hypoxia. Therefore, a low level of inflammation exists in the testis affecting adversely expressions of the androgen production genes such as StAR and 3-beta-HSD. The low inflammatory situation is always characterized by increasing chaperones of endoplasmic reticulum stress (ER stress). Endoplasmic reticulum (ER), a membraneenclosed reticular network, is the site for the maturation of newly synthesized proteins requiring appropriate folding process through various spatial configurations [6]. Hypoxia causes an excess of oxidants including both ROS (reactive oxygen species) and RNS (reactive nitrogen species) interfering with the process of unfolded protein response (UPR) [7]. At the beginning, UPR is favorable for cell-protecting activity possibly leading to a relief to ER stress. Along with the further development of ER stress, the signals such as IRE1 (inositol-requiring enzyme-1), PERK (double-strand RNA-activated protein kinase-like ER kinase), ATF6 (activating transcription factor-6) and CHOP (C/EBP homologous protein) are exaggerated, then, the dialogue between the endoplasmic reticulum and the nucleus is altered, triggering the signaling cascades to induce adverse events in cells, finally resulting in apoptosis, cell death and disease [8].

Stress, stimulated by oxygen deprivation, adversely affects the testis by reducing sperm genesis, histological changes associated with low testosterone production $[9,10]$. In our previous reports hypoxic pulmonary hypertension $(\mathrm{HPH})$ where oxidative stress develops is subsequent to an activation of the ET-ROS pathway $[11,12]$. Downregulation of FKBP12.6 and SERCA2a at the endoplasmic reticulum (ER) in cardiac myocytes is associated with an upregulated endothelin (ET) system facilitating ROS genesis $[13,14]$. Exaggerated production of ROS causes telomere shortened, spermatogenesis decreased and testosterone biosynthesis reduced, these abnormalities are likely to happen in aging [15]. Disturbance of ER function regarding calcium homeostasis induces abnormal protein folding process through ER stress and the UPR [16]. Eventually, ER stress facilitates the appearance of apoptosis through activating calcium homeostasis and exaggerated ROS production, accounting for cell dysfunction, insults and death [17]. However, it is unclear if hypoxia induced downregulated StAR and 3-beta-HSD and low testosterone in plasma are due to an involvement of ER stress in the hypoxia testis and these abnormalities could be blunted by interventions with calcium antagonism.

CPU86017, a derivative of berberine, has been reported to have calcium antagonism, $\alpha$-adrenoceptor blocking effects and antioxidative activities [18]. CPU86017 is a racemate, containing two chiral centers: $7 \mathrm{~N}$ and $13 \mathrm{aC}$, and the 4 isomers are active in suppressing L-type channels similar to those of the racemate. Among them, the activity of RS isomer is most favorable in treating hypoxic pulmonary hypertension [19].

We hypothesized that ER stress might be actively implicated in the hypoxic testicular injuries likely mediated by an increase in calcium influx which is augmented on hypoxia [20]. Thus, a blockade on the calcium influx by nifedipine and CPU86017-RS might be beneficial in normalizing StAR, 3-beta-HSD, low testosterone, and the ER stress due to oxygen deprivation. This study was aimed to verify whether ER stress is responsible for low expression of StAR and 3-beta-HSD, and low testosterone involved in hypoxia-damaged testes and could be blunted by CPU86017-RS, compared to those of nifedipine.

\section{Materials and methods \\ Materials}

CPU86017-RS (RS), was synthesized by the Center of New Drug Discovery, China Pharmaceutical University and nifedipine (Nif) was purchased from Kangpu Drug Manufacturer, Changzhou, China. The MMLV RT (Moloney Murine Leukemia Virus Reverse Transcriptase; Promega, Madison, WI) and Taq DNA polymerase (Tiangen Biotech, Beijing, China) were purchased from Tianwei Company, Nanjing, China. Monoclonal mouse anti-StAR-IgG, anti-CHOP-IgG, polyclonal rabbit antiPERK-IgG and anti-Bip-IgG were purchased from Santa Cruz Biotechnology (Santa Cruz, CA); polyclonal rabbit anti-3-beta-HSD-IgG from Novus Biotechnology; HRP-conjugated polyclonal goat anti-mouse IgG and polyclonal goat anti-rabbit IgG from Boster Biological Technology, Wuhan, China

\section{Animals}

Adult male Sprague-Dawley rats, weighing 200-220 g, were obtained from The Zhejiang Experimental Animal Center in Hangzhou, Zhejiang Province, with a license No. SCXK20080033. The treatment of rats was strictly conformed to the Guideline of Handling Experimental Animals set up by the Science-Technology Bureau of Jiangsu Province, China.

\section{Hypoxia and Treatment}

Rats were randomly divided into seven groups $(\mathrm{n}=10)$ : control, hypoxia for 28 days, and hypoxia treated $(\mathrm{mg} / \mathrm{kg}$, p.o.) during the last 14 days with Nif (10) and 3 doses of RS isomer (20,40, 80), and normal rats treated with RS isomer (80). Hypoxia exposure was conducted according to the previous studies with some modifications $[11,19]$. Briefly, rats were housed in a normobaric chamber $8 \mathrm{~h}$ per day, and inside $\mathrm{O}_{2}$ concentration at $10 \pm 0.5 \%$ 
controlled by driving in $\mathrm{N}_{2}$ with an instant monitoring system. The hypoxia condition is equivalent to $6000 \mathrm{~m}$ highland. Rats were under hypoxia sustained for 4 weeks. Sufficient amount of soda lime and anhydrous calcium chloride was placed inside to absorb unnecessary $\mathrm{CO}_{2}$ and moisture. Rats in control and untreated groups were received an equal volume of $0.5 \%$ carboxy-methyl-cellulose $\mathrm{Na}(\mathrm{CMC}-\mathrm{Na})$.

\section{Histological evaluation}

The testicular tissue was fixed with $10 \%$ neutral formalin, embedded in paraffin, and sliced into 5-mm-thick pieces that were stained with routine hematoxylin-eosin (H-E) staining. The examination of all slices was conducted under light microscopy by a pathologist blinded to the experimental profile, and pictures were taken at $\times 200$ amplification [21].

\section{Biochemical assays}

Serum testosterone $(\mathrm{T})$ and luteinizing hormone (LH) were conducted by applying chemiluminescence assay as in previous reports [21]. The contents of malondialdehyde (MDA) and activities of glutathione peroxidase (GSH-px) and lactate dehydrogenase (LDH) were assayed following instructions of the kits provided by the Nanjing Jiancheng Bio-engineering Institute (China).

\section{Reverse transcription PCR}

The mRNA abundance of StAR, 3-beta-HSD, Bip, PERK and CHOP was measured by RT-PCR according to the previous reports [19]. Briefly, total RNA extraction from testicular tissue by Trizol reagent was reversely transcribed into cDNA using MMLV RT according to the manufacturer's introduction. RT-PCR was performed in a volume of $25 \mathrm{uL}$ with a 1- $\mu \mathrm{g}$ aliquot of cDNA, and the products were stained with ethidium bromide and detected under an ultraviolet lamp (GDS8000; Sygene, Cambridge, UK).
The densitometry of each band was analyzed using professional image analysis software, and the ratio of the target gene against the GAPDH internal standard was calculated. The nucleotide sequences of primers and PCR amplification conditions are listed in Table 1.

\section{Western blot analysis}

To conduct quantitative analysis of protein levels of StAR, 3-beta-HSD, Bip, PERK and CHOP, a portion of testicular tissue $(100 \mathrm{mg})$ was homogenized in four volumes of extraction buffer and then centrifuged at $10,000 \times \mathrm{g}$ at $4^{\circ} \mathrm{C}$ (for $10 \mathrm{~min}$. After the protein concentrations were determined, the supernatant was stored at $-20^{\circ} \mathrm{C}$ before use. Aliquots of samples were heated to $98^{\circ} \mathrm{C}$ in a loading buffer and fractionated on $10 \%$ sodium dodecyl sulfate polyacrylamide gel electrophoresis (SDSPAGE). Following the transfer to a nitrocellulose membrane and blocking with nonfat milk (5\%, w/v), the blot was incubated at $4^{\circ} \mathrm{C}$ overnight with specific primary antibody. Three washes later, the blot incubated with horseradish peroxidase (HRP)-conjugated goat secondary antibody IgG (Affinity Bioreagents; 1:1000) for $1 \mathrm{~h}$ at room temperature was detected with a DAB kit. The bands was visualized by an imaging acquisition (Labworks, UK) and quantified by densitometry. The relative abundance was obtained by normalizing the density of the tested proteins against that of $\beta$-actin [22].

\section{Statistical analysis}

All data were analyzed with SPSS 11.5 (USA) and presented as the means \pm SD. Statistical evaluation was conducted by one-way ANOVA. Then Bonferroni multiple comparison tests were applied to check the significance of differences; in checking the variances of two independent samples an Independent-Sample t-test was used. A probability value of $P<0.05$ was considered to be statistically significant.

Table 1 Sequence of primers and conditions used for RT-PCR amplification

\begin{tabular}{lll}
\hline Primers & Sequence of primers & PCR amplification conditions \\
\hline StAR & Sense:5'-CTCAACAACCAAGGAAGGCTGG-3' & $94^{\circ} \mathrm{C}, 60 \mathrm{~s} ; 56^{\circ} \mathrm{C}, 40 \mathrm{~s} ;$ \\
3-beta-HSD & Atisense:5'-GCAGGTGGGGCGTGTTCAGC-3' & $72^{\circ} \mathrm{C}, 40 \mathrm{~s} ; 30 \mathrm{cycles}$ \\
& Sense:5'-ACTGGCAAATTCTCCATAGCC-3' & $94^{\circ} \mathrm{C}, 30 \mathrm{~s} ; 60^{\circ} \mathrm{C}, 45 \mathrm{~s} ;$ \\
CHOP & Atisense:5'-GCTGAACAGTCGACCCTCCTT-3' & $72^{\circ} \mathrm{C}, 60 \mathrm{~s} ; 30 \mathrm{cycles}$ \\
& Sense:5'-TCTGCCTTTCGCTTTGAG-3' & $94^{\circ} \mathrm{C}, 40 \mathrm{~s} ; 55^{\circ} \mathrm{C}, 60 \mathrm{~s} ;$ \\
Bip & Atisense:5'-GCTTTGGGGGTGCTTGTG-3' & $72^{\circ} \mathrm{C}, 40 \mathrm{~s} ; 29 \mathrm{cycles}$ \\
& Sense:5'-CATCAATGAGCCAACAGC-3' & $94^{\circ} \mathrm{C}, 45 \mathrm{~s} ; 60^{\circ} \mathrm{C}, 60 \mathrm{~s} ;$ \\
PERK & Atisense: 5'-AGGTAGAGCGGACAGG-3' & $72^{\circ} \mathrm{C}, 45 \mathrm{~s} ; 26 \mathrm{cycles}$ \\
& Sense: 5'-GCCGATGGGATAGTGATG-3' & $94^{\circ} \mathrm{C}, 45 \mathrm{~s} ; 62^{\circ} \mathrm{C}, 60 \mathrm{~s} ;$ \\
GAPDH & Atisense: 5'-GCAGCCTCTACAATGTCTTCT-3' & $72^{\circ} \mathrm{C}, 45 \mathrm{~s} ; 28 \mathrm{cycles}$ \\
& Sense:5'-GCTGGGGCTCACCTGAAGG-3' & $94^{\circ} \mathrm{C}, 45 \mathrm{~s} ; 56^{\circ} \mathrm{C}, 60 \mathrm{~s} ;$ \\
\hline
\end{tabular}




\section{Results}

Testosterone and LH

Serum testosterone in the hypoxia group was decreased dramatically by $73.9 \%(P<0.01)$ relative to control. To detect changes in the hypothalamus-pituitary-testis axis (HPT axis), an elevated serum LH was found, up to 596\% $(P<0.01)$ compared to control. An increase of LH was due to the decreased inhibitory activity of serum testosterone on the HPT axis via the negative feedback mechanism. An elevated serum testosterone was responded dose-dependently to CPU86017-RS and Nif in association with a recovery of serum LH (Figure 1).

\section{MDA, GSH-px and LDH}

After exposure to hypoxia for 4 weeks, production of MDA was increased by $79.4 \%$ and $65.8 \%$ in serum and the testis $(P<0.01)$, relative to normal, respectively. In contrast, a reduction in the activities of serum GSH-px by $37.9 \%$ and $\mathrm{LDH}$ in testis by $41.1 \%(P<0.01)$ was found, compared to normal (Figure 2). The results indicated that the rat was suffering from oxidative insults leading to an increment in lipid peroxidation and reduced antioxidant activity both in serum and the testis, and a deficiency of energy supply in the testis was indicative of decreased activity of testicular LDH responsible for the decreased production of androgen and spermatogenesis in the seminiferous tubules.
CPU86017-RS and Nif eliminated these changes significantly as compared with the hypoxia alone.

\section{Histological changes}

In the normal testis with $\mathrm{H}+\mathrm{E}$ staining, the multilayered epithelial cells were arranged and packed orderly in the seminiferous tubules, and the reproductive epithelium tightly linked to the basement membrane of the tubules. The lumen of tubules was rich in spermatozoa and the interstitial cells were present in the gap between the tubules. Contorted structures were found in the hypoxia group by showing distorted and decreased layers of reproductive germ cells and far fewer spermatozoa leaving a large cavity at the center of lumen. The skeleton of multilayered epithelial cells and extracellular matrix was seriously disturbed in the tubules. Leydig cells disappeared at the gaps among the tubules. These changes were in agreement with low testosterone in serum. The histological abnormalities of the testis were greatly attenuated by interventions with CPU86017-RS in a dose related manner and Nif, respectively (Figure 3).

\section{StAR and 3-beta-HSD}

Responded to hypoxia, expressions of genes of StAR and 3-beta-HSD, engaging in the biosynthesis of testosterone, were downregulated in the abundance of mRNA by $40.7 \%(P<0.01)$ and $38.8 \%(P<0.01)$, respectively
A

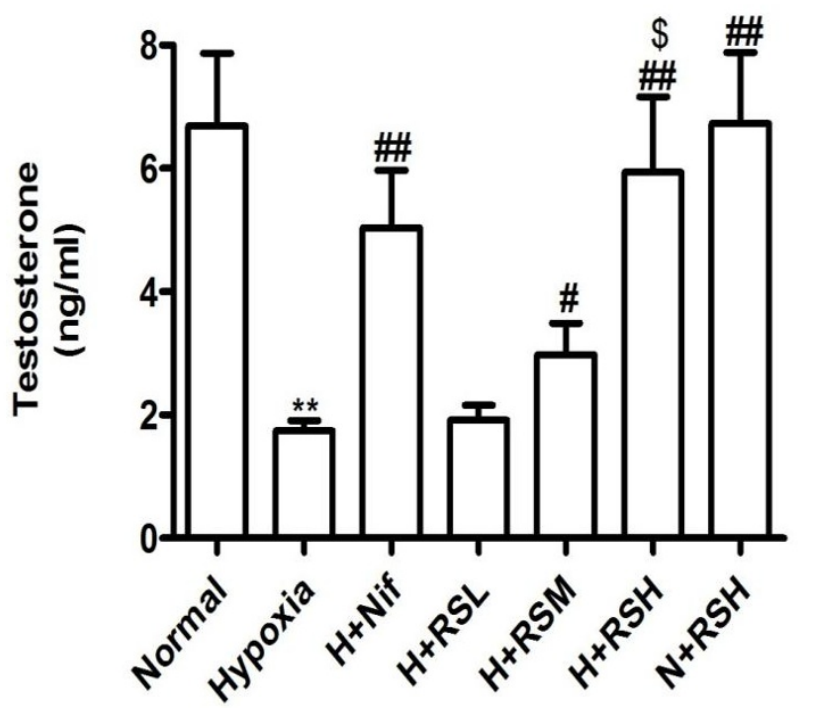

B

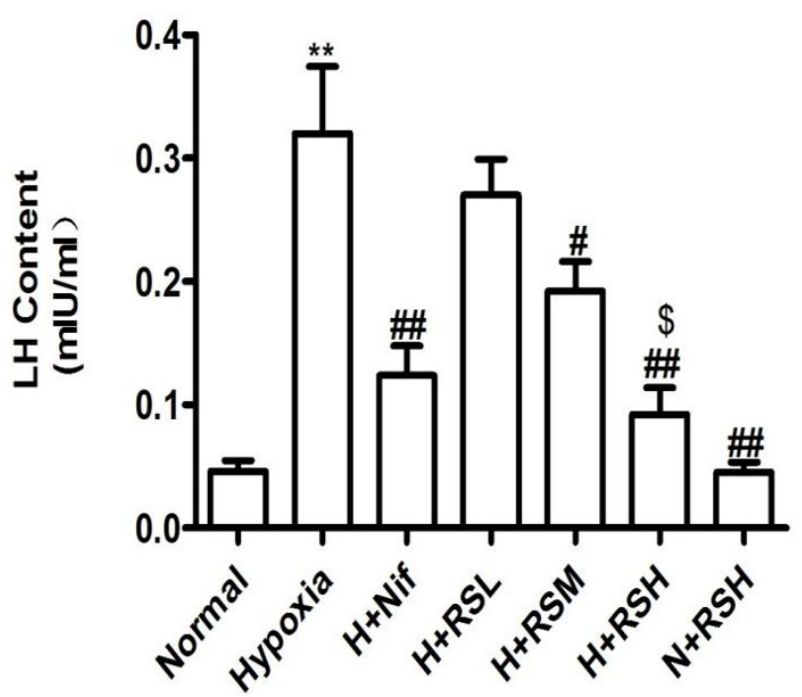

Figure 1 Serum testosterone and LH levels. A reduction in testosterone and an elevated LH in serum were found in rats explored to intermittent hypoxia for 4 weeks, and these changes were relieved by medication (mg/kg, po) with CPU86017-RS (20, 40, 80, termed as RSL, RSM, RSH) and Nif (10) in the last 2 weeks. A, Testosterone, and B, LH. Mean $\pm \mathrm{SD}, \mathrm{n}=10 .{ }^{*} P<0.05,{ }^{* *} P<0.01$, vs. Normal; ${ }^{\#} P<0.05$, ${ }^{\#} P<0.01$, vs. Hypoxia, ${ }^{\$} P<0.05$, vs. H+RSL (hypoxia + RS low dose). 


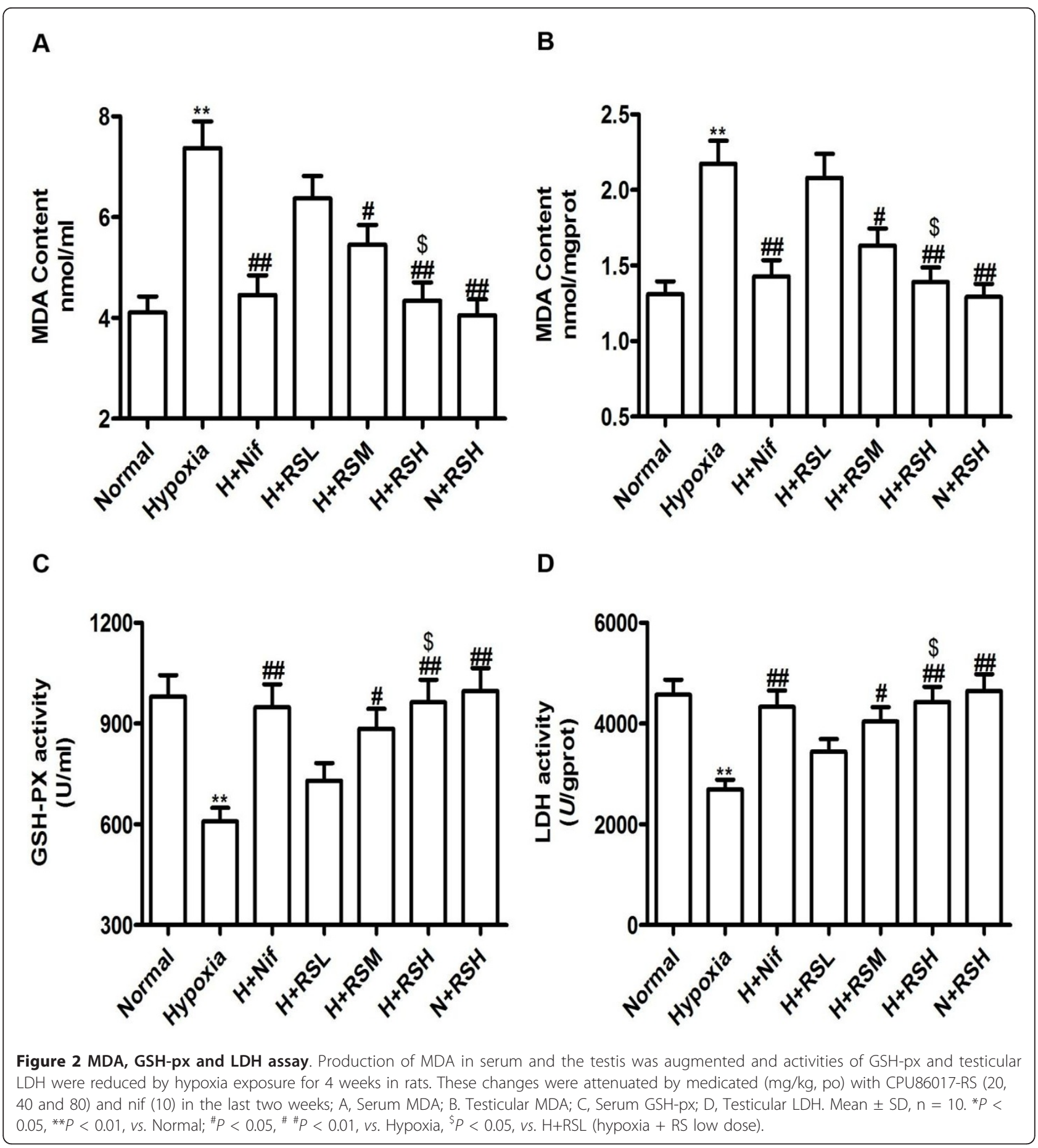

(Figure 4, A and 4C). Constantly, a reduction in protein abundance of StAR and 3-beta-HSD was evident by Western blot; down to $44.8 \%(P<0.01)$ and $41.1 \%(P<$ 0.01 ), relative to normal (Figure $4, B$ and $4 D$ ). In response to interventions these changes were attenuated markedly $(P<0.01)$ following application of 3 doses of CPU86017-RS and Nif as compared with the hypoxia group.

\section{Bip, PERK and CHOP}

It was interesting to verify if the hypoxic sufferings in the testis were characterized by an entity of inflammatory, thus, we tested the chaperones responsible for developing endoplasmic reticulum stress. An increase in mRNA expression of Bip, PERK and CHOP was significant $(\mathrm{P}<0.01)$ in the hypoxic testes, relative to normal. Protein abundances were upregulated significantly 


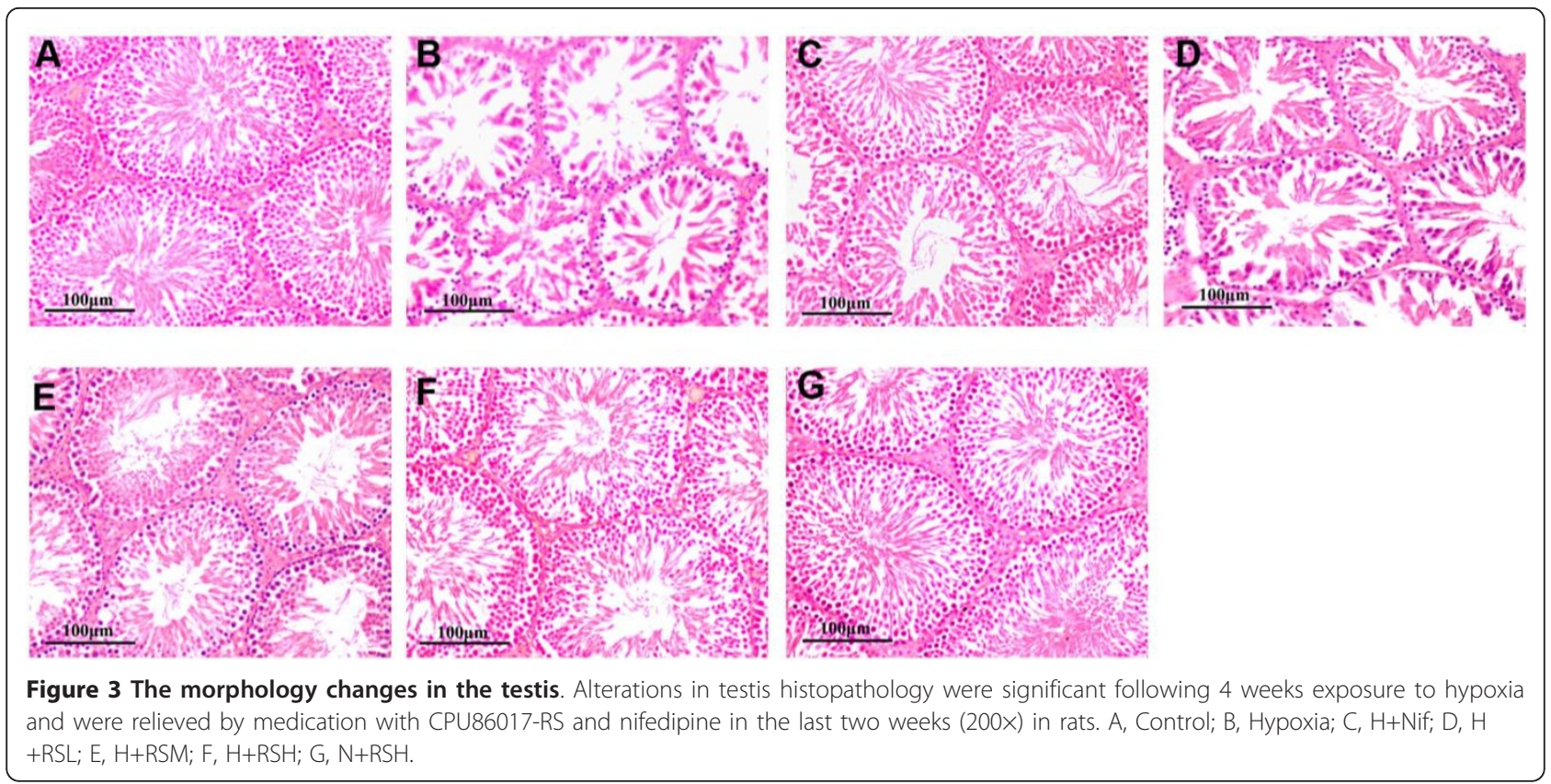

revealing the occurrence of ER stress which represented a status of chronic inflammation in the hypoxic testes. Following interventions, these abnormalities were greatly relieved, in agreement with the aforementioned findings. (Figure 5).

\section{Discussion}

In the present study, the testis damaged by intermittent hypoxia in rats is characterized by low testosterone and high LH in serum, associated with histological changes in the testis. Under oxygen deprivation, an increase in ROS and RNS has been found as contributing factors for tissue damage [5]. Emerging data indicates that ROS serves as the requisite effector and signaling regulator in facilitating hypoxic $\mathrm{Ca}^{2+}$ release [23]. Both calcium and ROS are regarded as the key messengers in the dialogue between ER and mitochondria. $\mathrm{Ca}^{2+}$ overload and excess ROS genesis may synergistically contribute to dysfunction of mitochondria and ER stress and eventually cell damage and death. As we demonstrated in the present study, an application of nifedipine, a calcium antagonist, is sufficient to blunt insults in the testis caused by intermittent hypoxia. It is coincided with the findings that calcium antagonists diltiazem and nifedipine are beneficial to low temperature-induced pulmonary hypertension associated with pulmonary vascular remodeling [24], and it is also true, as demonstrated in the present study, in relieving insults in the hypoxic testis.

In response to low serum testosterone, male hypogonadism can be divided into two categories: hypogonadotrophic, with a reduced FSH and LH against low testosterone, as presented in patients with diabetes, obesity, relevant to metabolic syndrome [25]. In contrast, a low serum testosterone is frequently involved in some acute events as responded to stress, exerting less suppression on the hypothalamus-pituitary connection, as a consequence, high levels of FSH and LH occur, referred as hypergonadotrophic hypogonadism. The latter is found in the present study on exposure to hypoxia, in line with those we reported previously in isoproterenol-induced testopathy [3].

The response to intermittent oxygen deprivation manifests an entity of stress and a low level of inflammation. These changes may be linked with an increase of ROS which stimulates an increase in calcium influx to facilitate overloaded $\mathrm{Ca}^{2+}$ in the cytosol. In the hypoxic pathologies in the testis, an increase in calcium influx is critical, thus, by a blockade on calcium influx, the decreased biosynthesis of testosterone in the testis and the response of the hypothalamus were blunted back to the normal levels. We suggested that $\mathrm{Ca}^{2+}$ overload injury may be caused by intermittent hypoxia in the testis which was associated with chronic inflammation, and these reactions were likely found in aging, characterized as progressively increase in ROS and degenerative changes in the testes [15].

StAR is a rate-limiting factor in testosterone biosynthesis, by transporting cholesterol from outer membrane of mitochondria to its inner side [26]. In Leydig cells, StAR expression is mainly regulated by LH-mediated activation of cAMP-dependent pathways leading to transcriptional activation ultimately [27]. It is reported that testicular damage is always presented with a reduced StAR gene expression in literatures $[28,29]$ and in our previous report [21]. The biosynthesis of androgen is completed in 


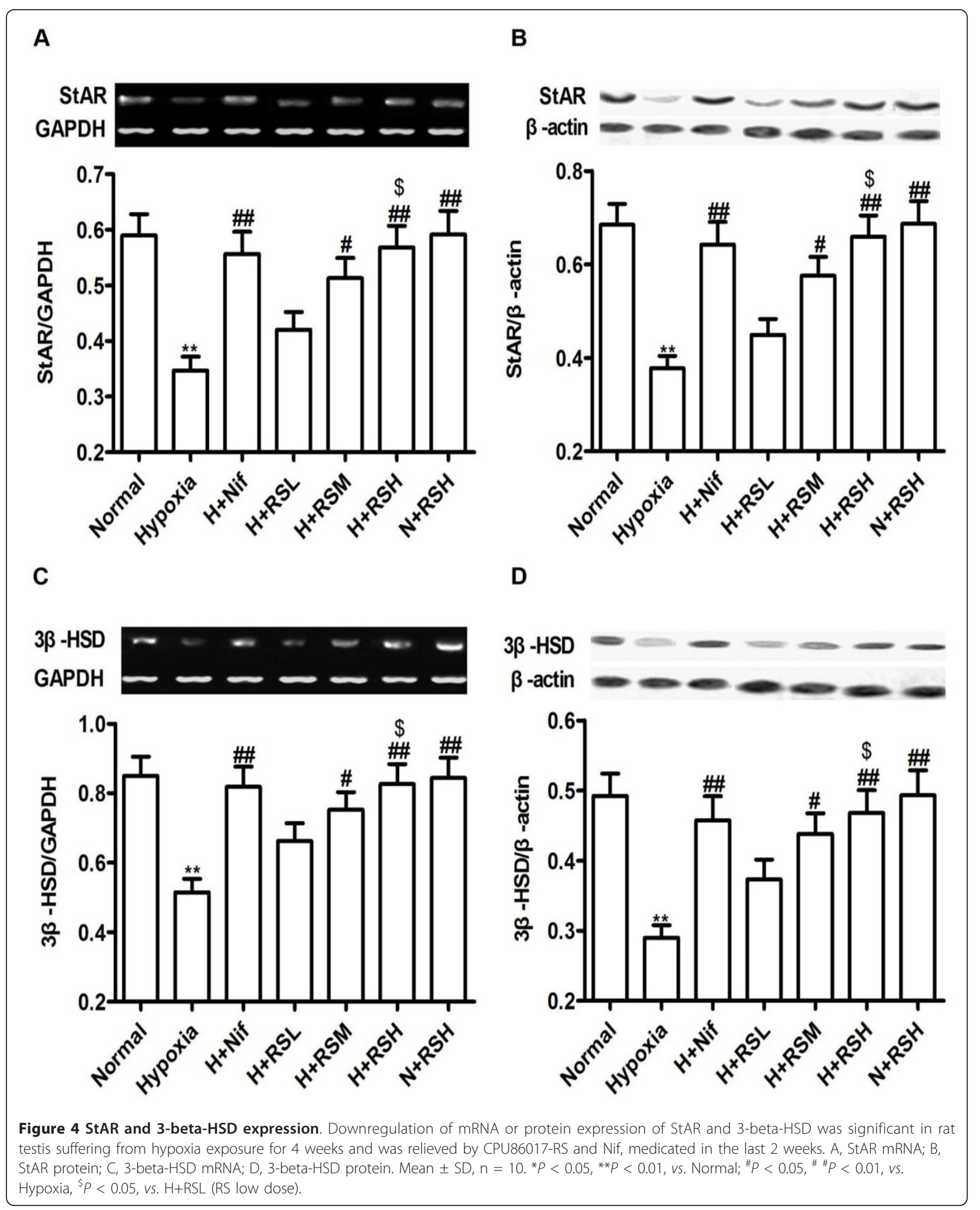


A
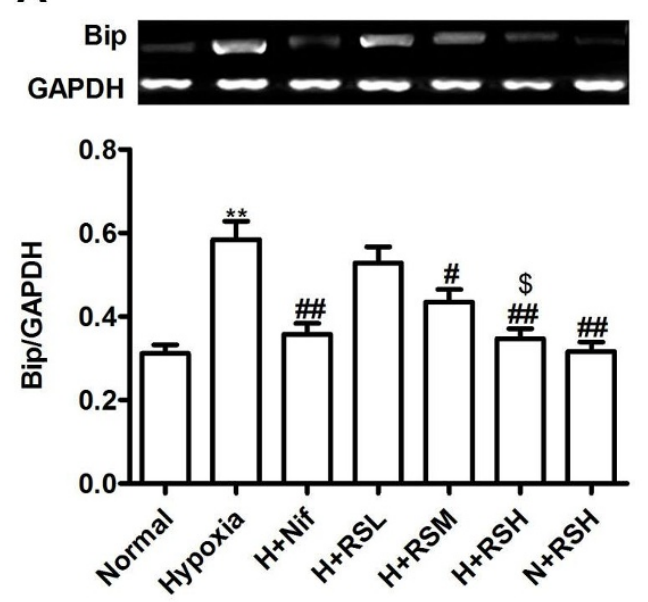

C
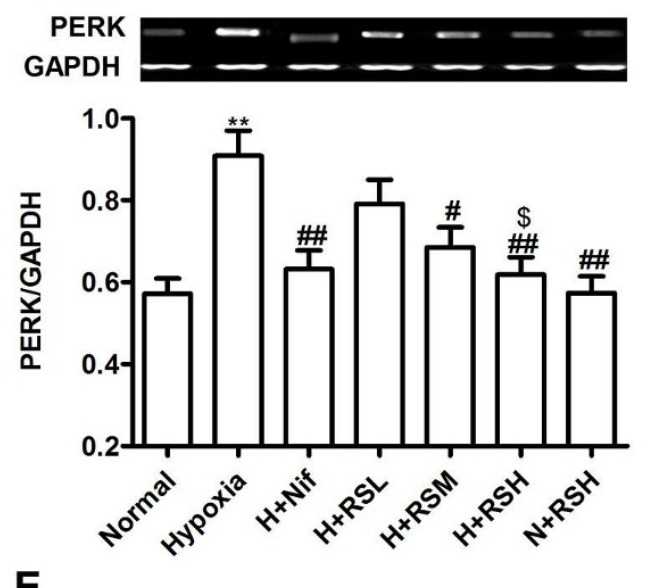

E
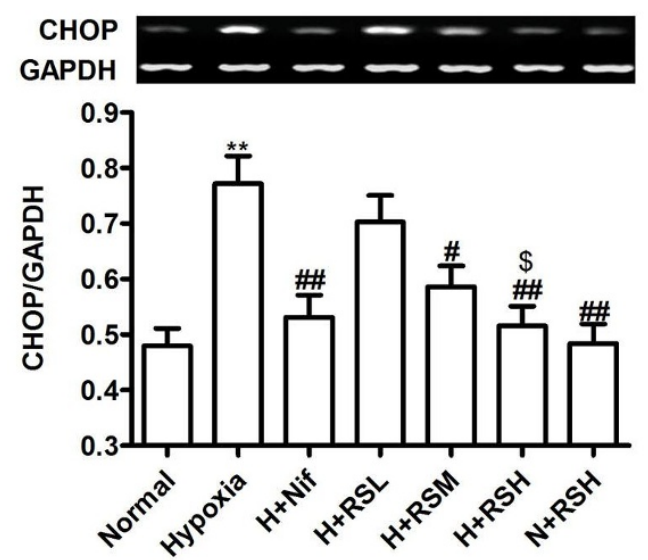

B
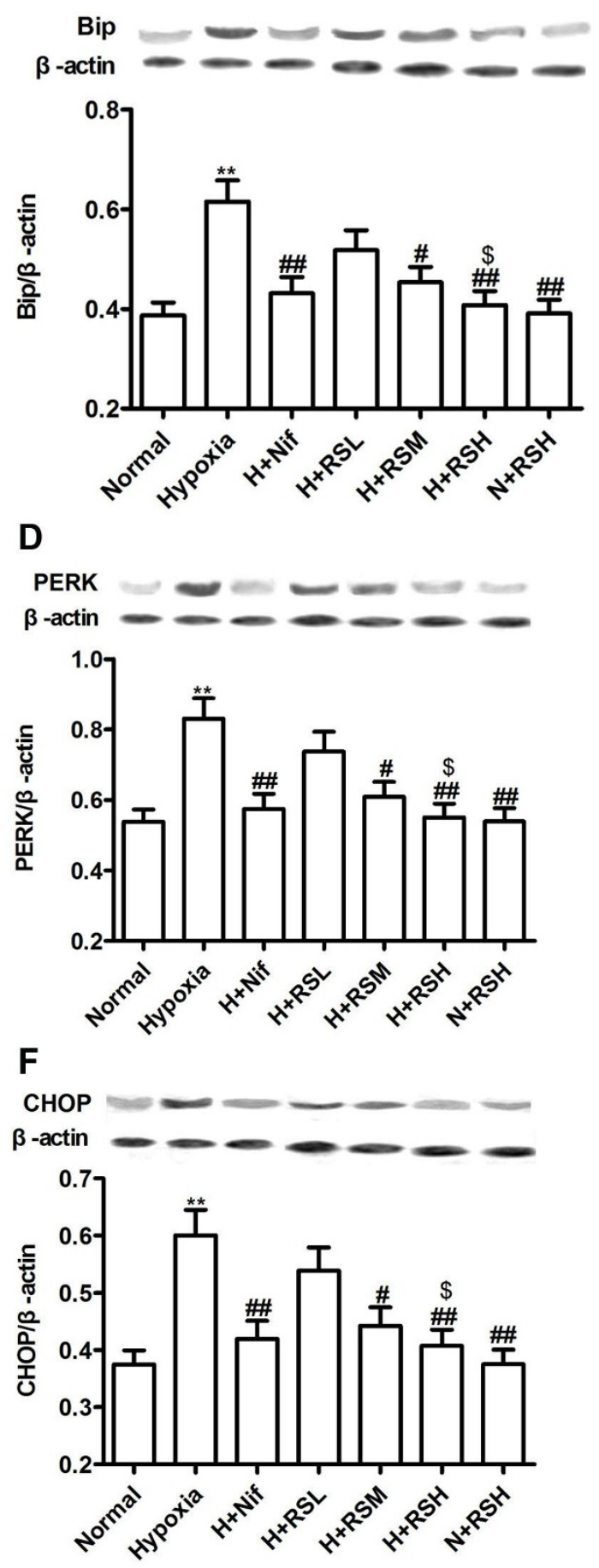

Figure 5 The expressions of ER stress chaperones. Upregulation of mRNA and protein expression of Bip, PERK and CHOP were caused by hypoxia in the testes and were attenuated by CPU86017-RS and Nif. A, Bip mRNA; B, Bip protein; C, PERK mRNA; D, PERK protein; E, CHOP

mRNA; F, CHOP protein. Mean $\pm \mathrm{SD}, \mathrm{n}=10 .{ }^{*} P<0.05$, ${ }^{*} P<0.01$, vs. Normal; ${ }^{\#} P<0.05,{ }^{\#}{ }^{\#} P<0.01$, vs. Hypoxia, ${ }^{\$} P<0.05, v$ s. H+RSL (hypoxia + RS low dose). 
serial reactions, in which 3-beta-HSD catalyzes the conversion of dehydroepiandrosterone to androstenedione in mitochondria, thereafter, the process of biosynthesis of testosterone is continued while moving into the ER in Leydig cells. The two enzymes presented a state of downregulation strongly indicating poor testosterone production in Leydig cells, eventually leading to a great decline in serum testosterone following hypoxia exposure [30].

ER stress has been expanded dramatically in explaining the entity of disease as low levels of inflammatory status in many diseases, and oxidative stress, calcium signaling and inflammatory factors have been recognized as the key messengers for inducing ER stress [16]. Regarding triggered factors in tissues, elevated pro-inflammatory cytokines, an excess of endothelin-1, hyperglycemia, hypercholesterolemia and disturbance of $\mathrm{Ca}^{2+}$ homeostasis are active in initiating ER stress. The UPR defined as a defensive response in its initial stage of ER stress, leading to a reduction in the ER workload by translational attenuation, then, the maladaptive response in the ER can be overcome. However, while risk factors, such as an excess of ROS genesis are persistent due to prolonged oxygen deprivation, more calcium influx into the cytoplasm can be seen in hypoxic pulmonary hypertension [11]. This situation could be reproduced in the hypoxic testis. In fact, in the present study, upregulation of Bip, identical to the $78 \mathrm{kDa}$ glucose regulated protein (GRP78), serves as a central regulator of ER stress and indicates its dissociation from the binding sites of the following chaperones ATF6, PERK and IRE1. Some studies using solid tumors showed that hypoxia induces Bip expression via activated ER stress to improve protein aggravation [31]. As demonstrated in the present study, a normal expression rather than an upregulated expression of Bip is essential in keeping the testis free from hypoxic insults.

PERK, a type I transmembrane kinase, can be activated by auto-phosphorylation and auto- dimerization following dissociation with Bip [32]. Activated PERK may rescue the cells from ER overload by phosphorylating eukaryotic initiation factor $2 \alpha($ IF $2 \alpha)$ at Ser 51, which inhibits mRNA translation in the nucleus. Cell protection in the hypoxic testes could be achieved by upregulation of PERK through reducing translation contributing to reduction of critical regulatory proteins which promotes activation of transcription factors such as $\mathrm{NF} \kappa-\mathrm{B}$ under cellular stress [33]. Important consequence of PERK- eIF2 $\alpha$ pathway could take place in the testis damaged by hypoxia exposure, the same as those showed in diabetic nephropathy which is characterized by upregulation of PERK in renal tissue [34].

ER stress, a double-edged sword, is beneficial at first, and appears to be harmful while upregulation of $\mathrm{CHOP} /$ GADD153 occurs. CHOP conducts the transition from the protective phase to the death-promoting phase of the UPR under intermittent hypoxia. Death executor CHOP induces apoptosis by promoting protein synthesis and oxidation in the stressed ER [35]. Many pathologies in the hypoxic testis are aggravated via CHOP-induced apoptosis. Our results indicate that significantly upregulated CHOP in the testis on chronic hypoxic exposure represents a severe damage to the testicular tissue due to ER stress. An increase in CHOP chaperone facilitates the appearance of apoptosis and testicular cell dysfunction possibly by suppressing Bcl-2 through JNK/CHOP/DR5 signaling [36], and stimulating Bim (BH3-only protein) via protein phosphatase $2 \mathrm{~A}$-mediated dephosphorylation and $\mathrm{CHOP}-\mathrm{C} / \mathrm{EBP} \alpha$-mediated transcriptional induction [37] and an enhancement of PUMA promoter through ATF4-CHOP pathway [38]. CHOP associated with severe testis damage was suppressed by CPU87017-RS and Nif.

The alteration of Bip, PERK and CHOP confirms that ER stress mediates the pathogenesis of testopathy under hypoxic exposure. Interestingly, inhibition of the $\mathrm{Ca}^{2+}$ influx by nifedipine is significant in this regards, indicating the importance of blockade on $\mathrm{Ca}^{2+}$ channels in attenuating ER stress in the hypoxic testis. Therefore, an alleviation of ER stress by CPU86017-RS is probably relevant to its calcium influx blocking activity in the hypoxic testis.

\section{Limitations}

As we revealed in the present study, the restricting of calcium influx is crucial in attenuating the testicular lesions by intermittent hypoxia. CPU86017-RS suppresses the calcium channels significantly $[11,18]$. We believe that CPU86017-RS and nifedipine exert beneficial effects relevant to the calcium antagonist activity in the testis, thereafter; a reduction in oxidative stress is the consequence by suppressing NADPH oxidase in the testis. However, direct suppression on NADPH oxidase and ROS genesis in Leydig cells by calcium influx restricting effects of CPU86017-RS and Nif are not offered in the present study. Downregulation of androgen biosynthesizing genes associated with exacerbated chaperones of ER stress in the Leydig cells is presumably modulated by calcium influx, which is needed for further exploration in the testicular dysfunction suffering from hypoxia.

\section{Conclusion}

Upregulation of Bip, PERK and CHOP is the major event in hypoxia testes in rats, contributing to low expression of StAR and 3-beta-HSD responsible for compromised testosterone biosynthesis. These changes are likely the consequence to an activation of an increased calcium influx in the testicular cells under oxygen deprivation. CPU86017-RS is potential for use in relieving hypoxiainduced testicular dysfunction through alleviating ER stress via its calcium antagonism. A restriction of calcium 
influx which modulates ER stress and the StAR and 3beta-HSD gene expression is worth to explore further in Leydig cells.

\begin{abstract}
Abbreviations
3-beta-HSD: 3-beta-hydroxysteroid dehydrogenase; Bip: Immunoglobulin heavy chain binding protein; CHOP: C/EBP homologous protein; CPU86017RS: (+)-7R, 13aS-p-chlorobenzyltetrahydroberberine chloride; ER: Endoplasmic reticulum; ER stress: Endoplasmic reticulum stress; FSH: follicle-stimulating hormone; HPH: hypoxic pulmonary hypertension; HPT axis: hypothalamuspituitary-testis axis; LH: luteinizing hormone; PERK: Double-strand RNAactivated protein kinase-like ER kinase; RNS reactive nitrogen species; ROS: Reactive oxygen species; StAR: Steroidogenic acute regulatory protein; UPR: Unfolded protein response.
\end{abstract}

\section{Acknowledgements}

This work was supported by National Key New Drug Innovation Program, The Ministry of Science and Technology of China, No: 2009ZXJ09004-070 and The National Natural Science Foundation of China No: 81070145.

\section{Authors' contributions}

DZD and YD conceived of the study, coordinated all studies and helped to draft and revise the manuscript. GLL and FY conducted biochemistry assay and the quantification of gene expression and drafted the manuscript. GLZ was responsible for conducting the hypoxic exposure of rats. CZ synthesized CPU86017-RS. All authors read and approved the manuscript.

\section{Competing interests}

The authors declare that they have no competing interests.

Received: 30 August 2011 Accepted: 8 January 2012

Published: 8 January 2012

\section{References}

1. Taylor F, Levine L: Clomiphene citrate and testosterone gel replacement therapy for male hypogonadism: efficacy and treatment cost. J Sex Med 2010, 7:269-276.

2. Mancini A, Leone E, Festa R, Grande G, Silvestrini A, de Marinis L, Pontecorvi A, Maira G, Littarru GP, Meucci E: Effects of testosterone on antioxidant systems in male secondary hypogonadism. J Androl 2008, 29:622-629.

3. Cheng YS, Dai DZ, Dai Y: Testis dysfunction by isoproterenol is mediated by upregulating endothelin receptor $A$, leptin and protein kinase Cvarepsilon and is attenuated by an endothelin receptor antagonist CPU0213. Reprod Toxicol 2010, 29:421-426.

4. Esteva S, Pedret R, Fort N, Torrella JR, Pages T, Viscor G: Oxidative stress status in rats after intermittent exposure to hypobaric hypoxia. Wilderness Environ Med 2010, 21:325-331.

5. Blokhina O, Fagerstedt KV: Oxidative metabolism, ROS and NO under oxygen deprivation. Plant Physiol Biochem 2010, 48:359-373.

6. Gorlach A, Klappa P, Kietzmann T: The endoplasmic reticulum: folding, calcium homeostasis, signaling, and redox control. Antioxid Redox Signal 2006, 8:1391-1418.

7. Dara L, Ji C, Kaplowitz N: The contribution of ER stress to liver diseases. Hepatology 2011.

8. Gewandter JS, Staversky RJ, O'Reilly MA: Hyperoxia augments ER-stressinduced cell death independent of BiP loss. Free Radic Biol Med 2009. 47:1742-1752

9. Collodel G, Moretti E, Fontani V, Rinaldi S, Aravagli L, Sarago G, Capitani S, Anichini C: Effect of emotional stress on sperm quality. Indian J Med Res 2008, 128:254-261.

10. Gundogan M, Yeni D, Avdatek F, Fidan AF: Influence of sperm concentration on the motility, morphology, membrane and DNA integrity along with oxidative stress parameters of ram sperm during liquid storage. Anim Reprod Sci 2010, 122:200-207.

11. Zhang TT, Cui B, Dai DZ, Tang XY: Pharmacological efficacy of CPU 86017 on hypoxic pulmonary hypertension in rats: mediated by direct inhibition of calcium channels and antioxidant action, but indirect effects on the ET-1 pathway. J Cardiovasc Pharmacol 2005, 46:727-734.
12. Cui B, Feng Y, Dai DZ, Dai Y: CPU0213, a novel endothelin receptor antagonist, relieves hypoxic pulmonary hypertension in rats by suppressing excessive ET-ROS pathway. Drug Dev Res 2007, 68:42-50

13. Qi MY, Xia HJ, Dai DZ, Dai Y: A novel endothelin receptor antagonist CPU0213 improves diabetic cardiac insufficiency attributed to upregulation of the expression of FKBP12.6, SERCA2a, and PLB in rats. J Cardiovasc Pharmacol 2006, 47:729-735.

14. Feng $Y$, Tang $X Y$, Dai DZ, Dai $Y$ : Reversal of isoproterenol-induced downregulation of phospholamban and FKBP12.6 by CPU0213-mediated antagonism of endothelin receptors. Acta Pharmacol Sin 2007, 28:1746-1754.

15. Desai N, Sabanegh E Jr, Kim T, Agarwal A: Free radical theory of aging: implications in male infertility. Urology 2010, 75:14-19.

16. Zhang K: Integration of ER stress, oxidative stress and the inflammatory response in health and disease. Int I Clin Exp Med 2010, 3:33-40.

17. Kim J, Choi TG, Ding Y, Kim Y, Ha KS, Lee KH, Kang I, Ha J, Kaufman RJ, Lee J, Choe W, Kim SS: Overexpressed cyclophilin B suppresses apoptosis associated with ROS and Ca2+ homeostasis after ER stress. J Cell Sci 2008, 121:3636-3648.

18. Dai DZ: CPU86017: a novel Class III antiarrhythmic agent with multiple actions at ion channels. Cardiovasc Drug Rev 2006, 24:101-115.

19. Li N, Dai DZ, Dai Y: CPU86017 and its isomers improve hypoxic pulmonary hypertension by attenuating increased ETA receptor expression and extracellular matrix accumulation. Naunyn Schmiedebergs Arch Pharmacol 2008, 378:541-552.

20. Hirenallur SD, Haworth ST, Leming JT, Chang J, Hernandez G, Gordon JB, Rusch NJ: Upregulation of vascular calcium channels in neonatal piglets with hypoxia-induced pulmonary hypertension. Am J Physiol Lung Cell Mol Physiol 2008, 295:L915-924.

21. Feng Y, Zhang Q, Dai DZ, Ying HJ, Dai Y: Strontium fructose 1,6diphosphate rescues adenine-induced male hypogonadism and upregulates the testicular endothelin-1 system. Clin Exp Pharmacol Physiol 2007, 34:1131-1137.

22. Zhang GL, Dai DZ, Xi T, Cong XD, Zhang Y, Dai Y: Isoproterenol-induced FKBP12.6/12 downregulation is modulated by ETA and ETB receptors and reversed by argirhein, a derivative of rhein. Acta Pharmacol Sin 2011, 32:223-229.

23. Wang YX, Zheng YM: Role of ROS signaling in differential hypoxic Ca2+ and contractile responses in pulmonary and systemic vascular smooth muscle cells. Respir Physiol Neurobiol 2010, 174:192-200.

24. Yang Y, Gao M, Guo Y, Qiao J: Calcium antagonists, diltiazem and nifedipine, protect broilers against low temperature-induced pulmonary hypertension and pulmonary vascular remodeling. Anim Sci J 2010, 81:494-500.

25. Dandona P, Dhindsa S, Chaudhuri A, Bhatia V, Topiwala S: Hypogonadotrophic hypogonadism in type 2 diabetes. Aging Male 2008, 11:107-117.

26. Miller WL: StAR search-what we know about how the steroidogenic acute regulatory protein mediates mitochondrial cholesterol import. $\mathrm{Mol}$ Endocrinol 2007, 21:589-601.

27. Martin LJ, Tremblay JJ: Glucocorticoids antagonize cAMP-induced Star transcription in Leydig cells through the orphan nuclear receptor NR4A1.J Mol Endocrinol 2008, 41:165-175.

28. Luo DY, Yang G, Liu JJ, Yang YR, Dong Q: Effects of varicocele on testosterone, apoptosis and expression of StAR mRNA in rat Leydig cells. Asian J Androl 2011, 13:287-291.

29. Wang H, Wang Q, Zhao XF, Liu P, Meng XH, Yu T, Ji YL, Zhang H, Zhang C, Zhang $Y, X u$ DX: Cypermethrin exposure during puberty disrupts testosterone synthesis via downregulating StAR in mouse testes. Arch Toxicol 2010, 84:53-61.

30. Schlinger BA, Pradhan DS, Soma KK: 3beta-HSD activates DHEA in the songbird brain. Neurochem Int 2008, 52:611-620.

31. Li J, Lee AS: Stress induction of GRP78/BiP and its role in cancer. Curr Mol Med 2006, 6:45-54.

32. Su Q, Wang S, Gao HQ, Kazemi S, Harding HP, Ron D, Koromilas AE: Modulation of the eukaryotic initiation factor 2 alpha-subunit kinase PERK by tyrosine phosphorylation. J Biol Chem 2008, 283:469-475.

33. Ron $D$, Walter $P$ : Signal integration in the endoplasmic reticulum unfolded protein response. Nat Rev Mol Cell Biol 2007, 8:519-529.

34. Hu C, Cong XD, Dai DZ, Zhang Y, Zhang GL, Dai Y: Argirein alleviates diabetic nephropathy through attenuating NADPH oxidase, $\mathrm{C} \times 43$, and 
PERK in renal tissue. Naunyn Schmiedebergs Arch Pharmacol 2011, 383:309-319.

35. Marciniak SJ, Yun CY, Oyadomari S, Novoa I, Zhang Y, Jungreis R, Nagata K, Harding HP, Ron D: CHOP induces death by promoting protein synthesis and oxidation in the stressed endoplasmic reticulum. Genes Dev 2004, 18:3066-3077.

36. Tiwary R, Yu W, Li J, Park SK, Sanders BG, Kline K: Role of endoplasmic reticulum stress in alpha-TEA mediated TRAIL/DR5 death receptor dependent apoptosis. PLoS One 2010, 5:e11865.

37. Puthalakath $H$, O'Reilly LA, Gunn P, Lee L, Kelly PN, Huntington ND, Hughes PD, Michalak EM, McKimm-Breschkin J, Motoyama N, Gotoh T, Akira S, Bouillet P, Strasser A: ER stress triggers apoptosis by activating BH3-only protein Bim. Cell 2007, 129:1337-1349.

38. Galehdar Z, Swan P, Fuerth B, Callaghan SM, Park DS, Cregan SP: Neuronal apoptosis induced by endoplasmic reticulum stress is regulated by ATF4-CHOP-mediated induction of the Bcl-2 homology 3-only member PUMA. J Neurosci 2010, 30:16938-16948.

doi:10.1186/1423-0127-19-4

Cite this article as: Liu et al: Endoplasmic reticulum stress mediating downregulated StAR and 3-beta-HSD and low plasma testosterone caused by hypoxia is attenuated by CPU86017-RS and nifedipine. Journal of Biomedical Science 2012 19:4.

\section{Submit your next manuscript to BioMed Central} and take full advantage of:

- Convenient online submission

- Thorough peer review

- No space constraints or color figure charges

- Immediate publication on acceptance

- Inclusion in PubMed, CAS, Scopus and Google Scholar

- Research which is freely available for redistribution

Submit your manuscript at www.biomedcentral.com/submit
Ciomed Central 